Article

\title{
The Convergence of Gallego's Iterative Method for Distribution-Free Inventory Models
}

\author{
Ting-Chen $\mathrm{Hu}^{1}{ }^{1}$, Kuo-Chen Hung ${ }^{2}$ and Kuo-Lung Yang ${ }^{2, *}$ \\ 1 Department of Health Business Administration, Hungkuang University, Taichung City 43302, Taiwan; \\ htc@sunrise.hk.edu.tw \\ 2 Department of Computer Science and Information Management, Hungkuang University, \\ Taichung City 43302, Taiwan; kchung@sunrise.hk.edu.tw \\ * Correspondence: yangklung@hk.edu.tw; Tel.: +886-9-3786-8127
}

Received: 16 April 2019; Accepted: 23 May 2019; Published: 27 May 2019

check for updates

\begin{abstract}
For inventory models with unknown distribution demand, during shortages, researchers used the first and the second moments to derive an upper bound for the worst case, that is the min-max distribution-free procedure for inventory models. They applied an iterative method to generate a sequence to obtain the optimal order quantity. A researcher developed a three-sequence proof for the convergence of the order quantity sequence. We directly provide proof for the original order quantity sequence. Under our proof, we can construct an increasing sequence and a decreasing sequence that both converge to the optimal order quantity such that we can obtain the optimal solution within the predesigned threshold value.
\end{abstract}

Keywords: inventory models; minimax distribution-free procedure

\section{Introduction}

In this paper, we directly prove that the iterative sequence proposed by Gallego [1] is convergent. Gallego [1] provided an upper bound to estimate the shortage during the lead time for stochastic demand inventory models, where the distribution of the demand is unknown but the first and the second moments are known. Gallego [1] focused on proving his upper bound as a good estimation without paying attention to the existence and uniqueness of the optimal solution. His new inventory model is complicated so that no closed formula for the optimal solution could be found. Moreover, his optimal solution is expressed by an implicit relation to imply a sequence solution. Additionally, Gallego [1] did not prove his sequence to converge toward its optimal solution. Since the publication of his approach, it has been cited 47 times. These papers can be classified into the following four categories:

(a) The construction of new inventory models: Qi et al. [2], Şen and Talebian [3], Wang et al. [4], Kumar and Goswami [5], Sarkar et al. [6], Yu and Zhai [7], Qin and Kar [8], Yu and Zhen [9], Moon et al. [10], Tajbakhsh [11], Gallego and ŞAhin [12], Perakis and Roeis [13], Ahmed et al. [14], Levin et al. [15], Mostard et al. [16], Alfares and Elmorra [17], Lin [18], Hariga and Ben-Daya [19], Talluri and Van Ryzin [20], and Gallego [21].

(b) The development of new solution procedures: Fu et al. [22], Postek et al. [23], Zhou et al. [24], Wu and Warsing [25], Popescu [26], Gallego et al. [27], Chung et al. [28], Puerto and Fernández [29], Tyworth and O'Neill [30], Moon and Choi [31], Moon and Yun [32], and Baganha et al. [33].

(c) The application to solve decision-making problems: Du et al. [34], Wright [35], Wang et al. [36], Das and Maiti [37], Puerto and Rodríguez-Chía [38], Fricker and Goodhart [39], Vairaktarakis [40], Hariga [41], Hariga and Ben-Daya [42], and Platt et al. [43].

(d) The improvement of existing solution approaches: Tuan [44], Lin [45], Ruiz-Torres and Mahmoodi [46], Hung et al. [47], Lin et al. [48], and Lin and Chu [49]. 
Papers in categories (a), (b) and (c) did not discuss the solution procedure of Gallego [1], and so papers in categories (a), (b) and (c) are beyond the realm of our discussion. Only publications in category (d) are in the scope of our discussion, therefore an outline of their results is provided. There are three papers, Moon and Gallego [50], Wu and Ouyang [51] and Tung et al. [52] that are worthy of mentioning even they did not cite Gallego [1] in their references. For distribution-free inventory models, Gallego [1] used order quantity $Q$ and reorder point $R$ as decision variables. On the other hand, Moon and Gallego [50] applied order quantity $Q$ and safety factor $k$ as decision variables. Wu and Ouyang [51] extended Moon and Gallego [50] with defective items and provided an iterative sequence solution approach. Moreover, Tung et al. [52] showed that the optimal solution for inventory models of $\mathrm{Wu}$ and Ouyang [51] exists and is unique. Lin and Chu [49] verified that the optimal solution may not occur on the boundary for inventory models with a service-level constraint. Lin et al. [48] showed the existence and uniqueness of the optimal solution for the first partial derivative system proposed by Gallego [1] and Moon and Gallego [50]. Lin et al. [48] also showed that the iterative sequence solution of $\mathrm{Wu}$ and Ouyang [51] cannot be executed. Hung et al. [47] proved that the minimum may not happen on the boundary for inventory models with a service-level constraint. Ruiz-Torres and Mahmoodi [46] used simulation to show that their findings are much closer to the target service level which reduces the total holding cost. Lin [45] constructed a three-sequence method to prove the convergence of the sequence derived by Gallego [1]. We can claim that up to now, Lin [45] is the only paper that had provided proof for the convergence problem of Gallego [1] and Moon and Gallego [50]. However, her approach is too tedious that contains three sequences. In this paper, we will present a direct derivation for the original sequence proposed by Gallego [1]. Tuan [44] studied the restriction proposed by Gallego [1] to find a more general condition such that the term by term examination in the iterative algorithm proposed by Gallego [1] becomes unnecessary. Tuan [44] also pointed out that the direct proof for the original sequence proposed by Gallego [1] for its convergence will be an interesting research topic in the future. Thus, it motivates us to simplify the three-sequence approach of Lin [45] back to the original sequence generated by the expression of Gallego [1].

From the above discussion, we know that none of the aforementioned papers directly discussed the convergence for the iterative method proposed by Gallego [1]. The purpose of this paper is directly to verify that Gallego's iterative method is convergent.

\section{Notation and Assumptions}

To be compatible with Gallego [1], since our main concern is to prove the convergence of the sequence generated by Gallego [1], we adopted the same notation and assumptions of Gallego [1].

Notation

$D=$ average demand per unit of time.

$h=$ inventory carrying cost per item per unit of time.

$K=$ the fixed ordering cost per order.

$Q=$ order quantities per order.

$R=$ reorder point.

$\pi=$ unit shortage cost.

$\mu=$ mean of the lead time demand.

$\sigma^{2}=$ the variance of the lead time demand.

\section{Assumptions}

1. Backorder cost is proportional to the number of items back ordered and not to the time for which they are outstanding.

2. $\quad F$ is the cumulative distribution of the lead time demand. $F$ has known finite first and second moments with mean $\mu$ and variance $\sigma^{2}$ and then makes no assumptions on the distribution form of $F$. 
3. The inventory model is continuously reviewed. Replenishments are made when the inventory level drops to the reorder point $R$.

\section{Recap of Three Related Papers}

We recall the objective function for the stochastic inventory model with distribution-free demand in Gallego [1] as follows

$$
C(Q, \Delta)=\frac{K D}{Q}+h\left(\frac{Q}{2}+\Delta\right)+\frac{\pi D}{2 Q}\left(\sqrt{\Delta^{2}+\sigma^{2}}-\Delta\right) .
$$

Remark 1. In Lin et al. [48], they considered the same objective function, however, there was a typo in Lin et al. [48], and so the denominator of the third term in Equation (1) was typed as " $Q$ " which should be revised to " $2 Q$ ".

Gallego [1] took the partial derivatives with respect to $Q$ and $\Delta$ then he canceled out $\Delta$ to merge $\frac{\partial}{\partial Q} C(Q, \Delta)=0$ and $\frac{\partial}{\partial \Delta} C(Q, \Delta)=0$ into one Equation with a single variable, $Q$, to derive the next formula:

$$
Q=\sqrt{\frac{2 K D}{h}+\frac{D \pi \sigma}{h} \sqrt{\frac{h Q}{\pi D-h Q}}}
$$

under the condition $\pi D \geq 2 h Q$.

Gallego [1] had mentioned that based on Equation (2) an iterative method will generate a convergent sequence which will converge to the optimal solution. However, up to now, except for Lin [45], none had discussed the convergence problem proposed by Gallego [1].

Lin et al. [48] pointed out that the restriction should be revised from $\pi D \geq 2 h Q$ to $\pi D>2 h Q$, which they then used to prove that there is a unique root for the partial derivative system. However, they did not discuss theconvergence of the iterative method of Gallego [1].

Based on Moon and Gallego [50] and Tung et al. [52], Lin [45] developed three sequences: $\left(k_{i}\right)$, $\left(Q_{i}\right)$ and $\left(d_{i}\right)$, with the initial point $k_{0}=0$, and three relations:

$$
Q_{n+1}=\left(B_{1}+B_{2}\left(\sqrt{1+k_{n}^{2}}-k_{n}\right)\right)^{1 / 2}
$$

with $B_{1}=\frac{2 D}{h \delta}\left[A+c_{i}\left(L_{i-1}-L\right)+\sum_{j=1}^{i-1} c_{j}\left(b_{j}-a_{j}\right)\right]$ and $B_{2}=\frac{D \sigma}{h \delta}\left(\pi+\pi_{0}(1-\beta)\right) \sqrt{L}$,

$$
d_{n+1}=\frac{1}{2}\left(1-\beta+\frac{D\left(\pi+\pi_{0}(1-\beta)\right)}{h Q_{n+1}(1-E(p))}\right)
$$

and

$$
k_{n+1}=\frac{d_{n+1}-1}{\sqrt{2 d_{n+1}-1}}
$$

with $\delta=1-2 E(p)+E\left(p^{2}\right)+2\left(h_{1} / h\right) E(p(1-p))$, where $h_{1}$ is the holding cost for non-defective items, $h$ is the holding cost for defective items, and $p$ is the defective rate in an order lot. In Gallego [1], there are no defective items, then $p=0$ to imply that $(p)=0,\left(p^{2}\right)=0$ and $E(p(1-p))=0$. Hence, $\delta=1$.

Lin [45] proved that $\left(d_{n}\right)$ and $\left(k_{n}\right)$ are increasing sequences and $\left(Q_{n}\right)$ is a decreasing sequence bounded below by zero, so $\left(Q_{n}\right)$ converges and then both $\left(d_{n}\right)$ and $\left(k_{n}\right)$ are convergent. 


\section{Our Improvement}

The purpose of this paper is to provide proof that the following sequence

$$
Q_{n+1}=\sqrt{\frac{2 K D}{h}+\frac{D \pi \sigma}{h} \sqrt{\frac{h Q_{n}}{\pi D-h Q_{n}}}},
$$

under the condition $\left(Q_{n}\right)$ proposed by Gallego [1] that $\left(Q_{n}\right)$ indeed converges, and the value it converges to is the optimal solution. Hence, we can derive the convergence of Gallego's iterative method by the original sequence to simplify the three-sequence approach proposed by Lin [45]. We mention our main result in the following theorem.

Theorem 1. The ordering quantity sequence, proposed by Gallego [1], converges to its interior optimal solution.

Proof of Theorem 1. From the restriction of $\pi D>2 h Q_{n}$, we know that

$$
\frac{h Q_{n}}{D \pi-h Q_{n}}<1 .
$$

Using the restriction of $\pi D>2 h Q_{n}$, we derive an upper bound for the sequence $\left(Q_{n}\right)$ as,

$$
Q_{n}<\frac{D \pi}{2 h}
$$

On the other hand, we know that there is a natural lower bound for $\left(Q_{n}\right)$ as,

$$
0<Q_{n}
$$

From Equation (6), we derive that,

$$
Q_{n+1}^{2}-Q_{n}^{2}=\frac{D \pi \sigma}{h}\left(\frac{1}{\sqrt{\left(D \pi / h Q_{n}\right)-1}}-\frac{1}{\sqrt{\left(D \pi / h Q_{n-1}\right)-1}}\right) .
$$

By Equations (9) and (10), $Q_{n+1}>Q_{n}$ is equivalent to:

$$
\sqrt{\frac{D \pi}{h Q_{n-1}}-1}>\sqrt{\frac{D \pi}{h Q_{n}}-1}
$$

that is,

$$
Q_{n}>Q_{n-1}
$$

to derive that $\left(Q_{n}\right)$ is increasing, if $Q_{1}>Q_{0}$.

Similarly, we know that $Q_{n+1}<Q_{n}$, if $Q_{1}<Q_{0}$ to imply that $\left(Q_{n}\right)$ is decreasing.

For a selected initial point $Q_{0}$, there are three conditions: (a) $Q_{0}>Q_{1}$, (b) $Q_{0}<Q_{1}$, and (c) $Q_{0}=Q_{1}$ that may occur.

For condition (a), from $Q_{1}<Q_{0},\left(Q_{n}\right)$ is a decreasing sequence bound below by zero so it converges to its greatest lower bound.

In the following, we will prove that the greatest lower bound is greater than zero. Owing to $Q_{n}>0$ so we have $\lim _{n \rightarrow \infty} Q_{n} \geq 0$. By the way of contradiction, we assume that $\lim _{n \rightarrow \infty} Q_{n}=0$.

It implies that $\lim _{n \rightarrow \infty} Q_{n+1}=0$ and we compute the limit of Equation (6) for $n \rightarrow \infty$, then it yields that $0=\sqrt{\frac{2 K D}{h}}$ which is a contradiction so our assumption of $\lim _{n \rightarrow \infty} Q_{n}=0$ is not valid. Hence, we obtain that $\lim _{n \rightarrow \infty} Q_{n}>0$. 
Owing to $\lim _{n \rightarrow \infty} Q_{n}$ satisfies Equation (2), $\lim _{n \rightarrow \infty} Q_{n}$ is the optimal solution since Lin et al. [48] showed the existence and uniqueness of the optimal solution.

For condition (b), because $Q_{0}<Q_{1},\left(Q_{n}\right)$ is an increasing sequence bound above by $\sqrt{\frac{2}{h}(K D+\pi \sigma)}$, therefore, it converges to its least upper bound. By the same reasoning for the decreasing sequence, $\lim _{n \rightarrow \infty} Q_{n}$ is the optimal solution.

For condition (c), because $Q_{0}=Q_{1}$, this yields that $\left(Q_{n}\right)$ is a constant sequence so it converges to $Q_{0}$ which satisfies Equation (2) so it is the optimal solution.

Now, we combine the above findings to derive that for all three conditions $\left(Q_{n}\right)$ converges. and converges to the optimal solution.

By an analytical approach with calculus, Lin et al. [48] have already proved that there is a unique solution for the interior minimum.

Because of the limit point, $\lim _{n \rightarrow \infty} Q_{n}$, satisfies the partial derivative system so it must be the optimal solution. Therefore, $\left(Q_{n}\right)$ converges to the optimal solution, for all three conditions.

\section{Numerical Examples}

We will present two numerical examples to illustrate that the sequence of ordering quantity, $\left(Q_{n}\right)$, depending on the initial point, can be a decreasing sequence or an increasing sequence. However, Gallego [1] and Lin et al. [48] did not provide numerical examples in their paper, so that we refer to Lin [45] to decide the following data: $K=200, D=600, h=20, \pi=50$ and $\sigma=7$ for our numerical examples. We know that $\pi D / 2 h$ is an upper bound and 0 is a lower bound for the ordering quantity.

From Table 1, we construct a decreasing sequence that is a support for our analytical result as $Q_{1}<Q_{0}$, then we generate a decreasing sequence.

Table 1. A decreasing sequence.

\begin{tabular}{cccccccc}
\hline$Q_{0}$ & $Q_{1}$ & $Q_{2}$ & $Q_{3}$ & $Q_{4}$ & $Q_{5}$ & $Q_{6}$ & $Q_{7}$ \\
\hline 750 & 150 & 124.499 & 123.122 & 123.044 & 123.040 & 123.039 & 123.039 \\
\hline
\end{tabular}

For our second numerical example with respect to condition (b), we assume that $Q_{0}=0$ and using Equation (6) to derive the iterative sequence. The computation results are listed in the following Table 2.

Table 2. An increasing sequence.

\begin{tabular}{ccccccc}
\hline$Q_{0}$ & $Q_{1}$ & $Q_{2}$ & $Q_{3}$ & $Q_{4}$ & $Q_{5}$ & $Q_{6}$ \\
\hline 0 & 109.545 & 122.259 & 122.995 & 123.037 & 123.039 & 123.039 \\
\hline
\end{tabular}

From Table 2, we construct an increasing sequence that is numerical evidence for our analytical result as $Q_{1}>Q_{0}$ then we derive an increasing sequence.

From Table 1, the decreasing sequence, we derive that the limit is less than or equal to 123.039. From Table 2, the increasing sequence, we obtain that the limit is greater than or equal to 123.039. Hence, we find that the optimal order quantity, $Q=123.039$ up to the third decimal place.

Let us recall the order quantity sequence derived by $\operatorname{Lin}$ [45], where $\mathrm{Q}_{1}=271.444019$, $\mathrm{Q}_{2}=179.201796, \mathrm{Q}_{3}=171.872873, \mathrm{Q}_{4}=171.206597, \mathrm{Q}_{5}=171.145237, \mathrm{Q}_{6}=171.139579, \mathrm{Q}_{7}=171.139060$, $\mathrm{Q}_{8}=171.139014$, and $\mathrm{Q}_{9}=171.139014$.

From the above sequence, usually researchers have observed that the sequence decreases very slowly until $Q_{8}=Q_{9}$ such that they have accepted the optimal order quantity is 171.139014 , up to the sixth decimal place. 
We may hypothetically assume that $\mathrm{Q}_{10}=170.142368, \mathrm{Q}_{11}=170.141352, \mathrm{Q}_{12}=170.141351$, and $Q_{13}=170.141351$, that is the decreasing rate becomes very slow from $Q_{6}$ to $Q_{9}$, and then decreased again from $Q_{10}$ to $Q_{13}$. Hence, only apply a decreasing sequence, researchers did not know where the optimal solution is.

On the other hand, we can construct two sequences: in Table 1, a decreasing sequence, and in Table 2, an increasing sequence, such that we can derive the limit, that is, the optimal order quantity without any doubts.

In [45], the numerical data is different from our results, because Lin [45] considered inventory models with partial back order. In Gallego [1] and this paper, shortages are fully back order.

In the following, we develop an algorithm to decide a sequence solution, denoted as $Q^{\Delta}$, to approximate the optimal order quantity, $Q^{*}$, within the pre-designed threshold value. We assume that $Q_{0}=0$ and $Q_{1}=\sqrt{\pi D / 2 h}$, and then for $n=0,1,2, \ldots$,

$$
Q_{2 n+2}=\sqrt{\frac{2 K D}{h}+\frac{D \pi \sigma}{h} \sqrt{\frac{h Q_{2 n}}{\pi D-h Q_{2 n}}}},
$$

and

$$
Q_{2 n+3}=\sqrt{\frac{2 K D}{h}+\frac{D \pi \sigma}{h} \sqrt{\frac{h Q_{2 n+1}}{\pi D-h Q_{2 n+1}}}}
$$

Owing to $Q_{0}=0<Q_{2}=\sqrt{2 K D / h}$, we derive that $\left(Q_{2 n}\right)$ is an increasing sequence. Next, to check $Q_{1}>Q_{3}$, we need the following lemma.

Lemma 1. For inventory models proposed by Gallego [1], we claim that,

$$
8 h K+4 h \pi \sigma<\pi^{2} D
$$

Proof of Lemma 1. If $Q_{1}=\sqrt{\pi D / 2 h}$, then we compute that,

$$
\frac{4 h^{2}}{D}\left(Q_{1}^{2}-Q_{3}^{2}\right)=\pi^{2} D-(8 h K+4 h \pi \sigma)
$$

With the data $K=200, D=600, h=20, \pi=50$ and $\sigma=7$ from Lin [45], we derive that,

$$
8 h K+4 h \pi \sigma=6 \times 10^{4}
$$

and

$$
\pi^{2} D=15 \times 10^{7}
$$

such that the inequality in Equation (15) is reasonable.

Based on our Lemma, we imply that $Q_{1}>Q_{3}$ and then $\left(Q_{2 n+1}\right)$ is a decreasing sequence. We construct our algorithm in the following.

Step 1: For a given threshold value, $\varepsilon$, we assume that $Q_{0}=0$ and $Q_{1}=\sqrt{\pi D / 2 h}$.

Step 2: We check the distance between $Q_{2 n}$ and $Q_{2 n+1}$, and assume

$$
m=\min \left\{n: Q_{2 n+1}-Q_{2 n}<\varepsilon\right\}
$$

Step 3: Our approximated solution, denoted as $Q^{\Delta}$, is defined as

$$
Q^{\Delta}=\frac{1}{2}\left(Q_{2 m}+Q_{2 m+1}\right)
$$


We demonstrate our algorithm for a threshold value $\varepsilon=10^{-6}$. We list the decreasing sequence $\left(Q_{2 n+1}\right)$ in Table 3 and the increasing sequence $\left(Q_{2 n}\right)$ in Table 4 .

Table 3. A decreasing sequence to the sixth decimal place.

\begin{tabular}{cccccccc}
\hline$Q_{1}$ & $Q_{3}$ & $Q_{5}$ & $Q_{7}$ & $Q_{9}$ & $Q_{11}$ & $Q_{13}$ & $Q_{15}$ \\
\hline 750 & 150 & 124.498996 & 123.121659 & 123.044093 & 123.039467 & 123.039453 & 123.039452 \\
\hline
\end{tabular}

Table 4. An increasing sequence to the sixth decimal place.

\begin{tabular}{cccccccc}
\hline$Q_{0}$ & $Q_{2}$ & $Q_{4}$ & $Q_{6}$ & $Q_{8}$ & $Q_{10}$ & $Q_{12}$ & $Q_{14}$ \\
\hline 0 & 109.544512 & 122.258644 & 122.995305 & 123.036959 & 123.039311 & 123.039444 & 123.039452 \\
\hline
\end{tabular}

We compute $Q_{1}-Q_{0}, Q_{3}-Q_{2}, \ldots, Q_{13}-Q_{12}=9 \times 10^{-6}>\varepsilon$, until $Q_{15}-Q_{14}=0<\varepsilon$ such that we derive our approximated order quantity,

$$
Q^{\Delta}=\frac{1}{2}\left(Q_{14}+Q_{15}\right)=123.039452 .
$$

We consider the problem of what factor or parameters affect the speed of the convergence rate for the sequence generated by the iterative procedure proposed by Gallego [1].

We compute that:

$$
\begin{aligned}
& Q_{n+2}^{2}-Q_{n+1}^{2}=\frac{\pi D \sigma}{h}\left(\sqrt{\frac{h Q_{n+1}}{\pi D-h Q_{n+1}}}-\sqrt{\frac{h Q_{n}}{\pi D-h Q_{n}}}\right) \\
= & \frac{\pi D \sigma}{h}\left(\sqrt{\frac{h Q_{n+1}}{\pi D-h Q_{n+1}}}+\sqrt{\frac{h Q_{n}}{\pi D-h Q_{n}}}\right)^{-1}\left(\frac{h Q_{n+1}}{\pi D-h Q_{n+1}}-\frac{h Q_{n}}{\pi D-h Q_{n}}\right) \\
= & \frac{\pi D \sigma}{h}\left(\sqrt{\frac{h Q_{n+1}}{\pi D-h Q_{n+1}}}+\sqrt{\frac{h Q_{n}}{\pi D-h Q_{n}}}\right)^{-1}\left(\frac{\pi D h\left(Q_{n+1}-Q_{n}\right)}{\left(\pi D-h Q_{n+1}\right)\left(\pi D-h Q_{n}\right)}\right) .
\end{aligned}
$$

Based on Equation (22), when $n$ is big enough, we derive that,

$$
\left|Q_{n+2}-Q_{n+1}\right| \approx \frac{\pi^{2} D^{2} \sigma}{4\left(\left(\pi D-h Q^{*}\right) Q^{*}\right)^{1.5} h^{0.5}}\left|Q_{n+1}-Q_{n}\right| .
$$

First, we derive

$$
\frac{\pi^{2} D^{2} \sigma}{4\left(\left(\pi D-h Q^{*}\right) Q^{*}\right)^{1.5} h^{0.5}}=0.056464 .
$$

Next, we refer to Table 4, and find that,

$$
\begin{aligned}
& \frac{Q_{10}-Q_{8}}{Q_{8}-Q_{6}}=0.056469, \\
& \frac{Q_{12}-Q_{10}}{Q_{10}-Q_{8}}=0.056464,
\end{aligned}
$$

and

$$
\frac{Q_{14}-Q_{12}}{Q_{12}-Q_{10}}=0.056464 .
$$

If we compare Equations (24)-(27) to show that our estimation of the converge rate of Equation (24) is very accurate when $n$ is big enough after five iterations. 
To estimate which factor influences the converge rate, we consider $\pi D-h Q^{*} \approx \pi D$, and then we simplify our result of Equation (24) as,

$$
\sqrt{\frac{\pi D / h}{Q^{*}}} \frac{\sigma}{4 Q^{*}}=0.049685
$$

with

$$
\left(\sqrt{\frac{\pi D / h}{Q^{*}}} \frac{\sigma}{4 Q^{*}}\right) / \frac{\pi^{2} D^{2} \sigma}{4\left(\left(\pi D-h Q^{*}\right) Q^{*}\right)^{1.5} h^{0.5}}=0.049685 / 0.056464=0.88,
$$

to indicate $\sqrt{\frac{\pi D / h}{Q^{*}}} \frac{\sigma}{4 Q^{*}}$ can interpret $88 \%$ of the converge rate such that we claim that the main factors for the convergence rate are (i) $\sigma$, (ii) $\sqrt{(\pi D / h) / Q^{*}}$ and (iii) $Q^{*}$.

Finally, three related papers of Braglia et al. $[53,54]$ and Castellano et al. [55] are worth mentioning.

\section{Conclusions}

Our paper provides a patchwork for the Gallego's iterative method since its convergence has not yet been proven. Moreover, we showed that there are three possible conditions for convergence which is a generalization of Lin [45].

Author Contributions: Conceptualization, T.-C.H., K.-C.H.; methodology, T.-C.H., K.-C.H. and K.-L.Y.; software, K.-C.H., K.-L.Y.; validation, T.-C.H., K.-C.H.; formal analysis, T.-C.H., K.-C.H. and K.-L.Y.; investigation, T.-C.H., K.-C.H.; resources, T.-C.H., K.-L.Y.; data curation, K.-C.H. and K.-L.Y.; writing- original draft preparation, K.-C.H. and K.-L.Y.; writing-review and editing, T.-C.H., K.-C.H.; visualization, T.-C.H., K.-C.H.; supervision, T.-C.H., K.-C.H.; project administration, T.-C.H., K.-C.H.; funding acquisition, K.-C.H., K.-L.Y.

Funding: This research was funded by Ministry of Science and Technology, R.O.C. grant number MOST 107-2410-H-241-001.

Conflicts of Interest: The authors declare no conflict of interest.

\section{References}

1. Gallego, G. A minmax distribution-free procedure for the $(Q, R)$ inventory model. Oper. Res. Lett. 1992, 11, 55-60. [CrossRef]

2. Qi, A.; Ahn, H.S.; Sinha, A. Capacity investment with demand learning. Oper. Res. 2017, 65, 145-164. [CrossRef]

3. Şen, A.; Talebian, M. Markdown Budgets for Retail Buyers: Help or Hindrance? Prod. Oper. Manag. 2017, 26, 1875-1892. [CrossRef]

4. Wang, F.; Yu, H.; Sun, C.H. The model of new product supply chain under vendor-managed inventory with consignment and sales rebate. Syst. Eng. Theory Pract. 2013, 33, 2804-2810.

5. Kumar, R.S.; Goswami, A. A continuous review production-inventory system in fuzzy random environment: Minmax distribution free procedure. Comput. Ind. Eng. 2015, 79, 65-75. [CrossRef]

6. Sarkar, B.; Mandal, B.; Sarkar, S. Quality improvement and backorder price discount under controllable lead time in an inventory model. J. Manuf. Syst. 2015, 35, 26-36. [CrossRef]

7. Yu, H.; Zhai, J. The distribution-free newsvendor problem with balking and penalties for balking and stockout. J. Syst. Sci. Syst. Eng. 2014, 23, 153-175. [CrossRef]

8. Qin, Z.; Kar, S. Single-period inventory problem under uncertain environment. Appl. Math. Comput. 2013, 219, 9630-9638. [CrossRef]

9. Yu, H.; Zhen, X. Two-stage online distribution strategy of emergency material. Syst. Eng. Theory Pract. 2012, 32, 1924-1931.

10. Moon, I.; Ha, B.; Kim, J. Inventory systems with variable capacity. Eur. J. Ind. Eng. 2012, 6, 68-86. [CrossRef]

11. Tajbakhsh, M.M. On the distribution free continuous-review inventory model with a service level constraint. Comput. Ind. Eng. 2010, 59, 1022-1024. [CrossRef]

12. Gallego, G.; Şahin, O. Revenue management with partially refundable fares. Oper. Res. 2010, 58, 817-833. [CrossRef] 
13. Perakis, G.; Roeis, G. Regret in the newsvendor model with partial information. Oper. Res. 2008, 56, $188-203$. [CrossRef]

14. Ahmed, S.; Çakmak, U.; Shapiro, A. Coherent risk measures in inventory problems. Eur. J. Oper. Res. 2007, 182, 226-238. [CrossRef]

15. Levin, Y.; McGill, J.; Nediak, M. Price guarantees in dynamic pricing and revenue management. Oper. Res. 2007, 55, 75-97. [CrossRef]

16. Mostard, J.; De Koster, R.; Teunter, R. The distribution-free newsboy problem with resalable returns. Int. J. Prod. Econ. 2005, 97, 329-342. [CrossRef]

17. Alfares, H.K.; Elmorra, H.H. The distribution-free newsboy problem: Extensions to the shortage penalty case. Int. J. Prod. Econ. 2005, 93-94, 465-477. [CrossRef]

18. Lin, K.Y. A sequential dynamic pricing model and its applications. Nav. Res. Logist. 2014, 51, 501-521. [CrossRef]

19. Hariga, M.; Ben-Daya, M. Some stochastic inventory models with deterministic variable lead time. Eur. J. Oper. Res. 1999, 113, 42-51. [CrossRef]

20. Talluri, K.; Van Ryzin, G. An analysis of bid-price controls for network revenue management. Manag. Sci. 1998, 44, 1577-1593. [CrossRef]

21. Gallego, G.; Van Ryzin, G. A multiproduct dynamic pricing problem and its applications to network yield management. Oper. Res. 1997, 45, 24-41. [CrossRef]

22. Fu, Q.C.; Sim, K.; Teo, C.P. Profit sharing agreements in decentralized supply chains: A distributionally robust approach. Oper. Res. 2018, 66, 500-513. [CrossRef]

23. Postek, K.; Ben-Tal, A.; Den Hertog, D.; Melenberg, B. Robust optimization with ambiguous stochastic constraints under mean and dispersion information. Oper. Res. 2018, 66, 814-833. [CrossRef]

24. Zhou, J.; Wang, Y.; Yan, X. Joint Pricing and Purchasing Decisions for the Dual-Channel Newsvendor Model with Partial Information. J. Appl. Math. 2014, 2014, 954073. [CrossRef]

25. Wu, X.; Warsing, D.P. Comparing traditional and fuzzy-set solutions to $(Q, r)$ inventory systems with discrete lead-time distributions. J. Intell. Fuzzy Syst. 2013, 24, 93-104.

26. Popescu, I. A semidefinite programming approach to optimal-moment bounds for convex classes of distributions. Math. Oper. Res. 2005, 30, 632-657. [CrossRef]

27. Gallego, G.; Ryan, J.K.; Simchi-Levi, D. Minimax analysis for finite- horizon inventory models. IIE Trans. Inst. Ind. Eng. 2001, 33, 861-874. [CrossRef]

28. Chung, C.; Flynn, J.; Stalinski, P. A single-period inventory placement problem for a serial supply chain. Nav. Res. Logist. 2001, 48, 506-517. [CrossRef]

29. Puerto, J.; Fernández, F.R. Pareto-optimality in classical inventory problems. Nav. Res. Logist. 1998, 45, 83-98. [CrossRef]

30. Tyworth, J.E.; O'Neill, L. Robustness of the normal approximation of lead-time demand in a distribution setting. Nav. Res. Logist. 1997, 44, 165-186. [CrossRef]

31. Moon, I.; Choi, S. Distribution free procedures for make-to-order (MTO), make-in-advance (MIA), and composite policies. Int. J. Prod. Econ. 1997, 48, 21-28. [CrossRef]

32. Moon, I.; Yun, W. The distribution free job control problem. Comput. Ind. Eng. 1997, 32, 109-113. [CrossRef]

33. Baganha, M.P.; Pyke, D.F.; Ferrer, G. The undershoot of the reorder point: Tests of an approximation. Int. J. Prod. Econ. 1996, 45, 311-320. [CrossRef]

34. Du, D.; Chen, B.; Xu, D. Quantifying the efficiency of price-only contracts in push supply chains over demand distributions of known supports. Omega 2014, 42, 98-108. [CrossRef]

35. Wright, C.P. Decomposing airline alliances: A bid-price approach to revenue management with incomplete information sharing. J. Revenue Pricing Manag. 2014, 13, 164-182. [CrossRef]

36. Wang, B.; Adams, T.M.; Jin, W.; Meng, Q. The process of information propagation in a traffic stream with a general vehicle headway: A revisit. Transp. Res. Part C Emerg. Technol. 2010, 18, 367-375. [CrossRef]

37. Das, B.; Maiti, M. An application of bi-level newsboy problem in two substitutable items under capital cost. Appl. Math. Comput. 2007, 190, 410-422. [CrossRef]

38. Puerto, J.; Rodríguez-Chía, A.M. Robust positioning of service units. Stoch. Models 2003, 19, 125-147. [CrossRef]

39. Fricker, R.D.; Goodhart, C.A. Applying a bootstrap approach for setting reorder points in military supply systems. Nav. Res. Logist. 2000, 47, 459-478. [CrossRef] 
40. Vairaktarakis, G.L. Robust multi-item newsboy models with a budget constraint. Int. J. Prod. Econ. 2000, 66, 213-226. [CrossRef]

41. Hariga, M. A single-period, multi-echelon stochastic model under a mix of assemble to order and assemble in advance policies. Nav. Res. Logist. 1998, 45, 599-614. [CrossRef]

42. Hariga, M.; Ben-Daya, M. Note: The economic manufacturing lot-sizing problem with imperfect production processes: Bounds and optimal solutions. Nav. Res. Logist. 1998, 45, 423-433. [CrossRef]

43. Platt, D.E.; Robinson, L.W.; Freund, R.B. Tractable $(Q, R)$ heuristic models for constrained service levels. Manag. Sci. 1997, 43, 951-965. [CrossRef]

44. Tuan, H.W. Minimax distribution free procedure for inventory models. Int. J. Inf. Manag. Sci. 2018, 29, $115-125$.

45. Lin, J. A Study on iterative algorithm for stochastic distribution free inventory models. Abstr. Appl. Anal. 2013, 2013, 251694. [CrossRef]

46. Ruiz-Torres, A.J.; Mahmoodi, F. Safety stock determination based on parametric lead time and demand information. Int. J. Prod. Res. 2010, 48, 2841-2857. [CrossRef]

47. Hung, C.; Hung, K.; Tang, W.; Lin, R.; Wang, C. Periodic review stochastic inventory models with service level constraint. Int. J. Syst. Sci. 2009, 40, 237-243. [CrossRef]

48. Lin, R.; Chouhuang, W.T.; Yang, G.K.; Tung, C. An improved algorithm for the minimax distribution-free inventory model with incident-oriented shortage costs. Oper. Res. Lett. 2007, 35, 232-234. [CrossRef]

49. Lin, R.H.; Chu, P. Note on stochastic inventory models with service level constraint. J. Oper. Res. Soc. Jpn. 2006, 49, 117-129. [CrossRef]

50. Moon, I.; Gallego, G. Distribution free procedures for some inventory models. J. Oper. Res. Soc. 1994, 45, 651-658. [CrossRef]

51. Wu, K.S.; Ouyang, L.Y. (Q, r, L) Inventory model with defective items. Comput. Ind. Eng. 2001, 39, 173-185. [CrossRef]

52. Tung, C.T.; Wou, Y.W.; Lin, S.W.; Deng, P. Technical note on $(Q, r, L)$ inventory model with defective items. Abstr. Appl. Anal. 2010. [CrossRef]

53. Braglia, M.; Castellano, D.; Song, D. Distribution-free approach for stochastic joint-replenishment problem with backorders-lost sales mixtures, and controllable major ordering cost and lead times. Comput. Oper. Res. 2017, 79, 161-173. [CrossRef]

54. Braglia, M.; Castellano, D.; Song, D. Efficient near-optimal procedures for some inventory models with backorders-lost sales mixture and controllable lead time, under continuous or periodic review. Int. J. Math. Oper. Res. 2018, 13, 141-177. [CrossRef]

55. Castellano, D.; Gallo, M.; Santillo, L.C.; Song, D. A periodic review policy with quality improvement, setup cost reduction, backorder price discount, and controllable lead time. Prod. Manuf. Res. 2017, 5, 328-350. [CrossRef]

(C) 2019 by the authors. Licensee MDPI, Basel, Switzerland. This article is an open access article distributed under the terms and conditions of the Creative Commons Attribution (CC BY) license (http://creativecommons.org/licenses/by/4.0/). 